\title{
East/West Nature of ANZACATA: A Perspective on the Significance of International Connections while Asserting Southeast Asian Relevance and Context in Practice and in Postgraduate Art Therapy Training
}

\author{
Ronald P.M.H. Lay \\ LASALLE College of the Arts, Singapore
}

\begin{abstract}
The Australian, New Zealand and Asian Creative Arts Therapies Association (ANZACATA) is uniquely positioned, geographically and philosophically, in terms of art therapy practice, training, and the ongoing development of this discipline in the Asia Pacific region. Acknowledgement of, respective for, and an embracing of culture, cultural traditions, and practices that are culturally relevant are some of the fundamentals at the core of this art therapy membership organization. A critical and multipronged relationship has been established among ANZACATA, Singapore, and the MA Art therapy training program at LASALLE College of the Arts, Singapore. This article presents a perspective on the development of art therapy in Southeast Asia with consideration to the significance of East/West influences, relations, and training. The aim is to provide a reflective account of the unique East/West nature and role of ANZACATA and on art therapy in Singapore through my role as program leader of the first and only postgraduate psychodynamic art psychotherapy training in Southeast Asia. This perspective is further informed through substantial experience as a credentialed art therapist bridging Eastern and Western countries, cultures, clinical practices, and professional art(s) therapy organizations. This article was written and articulated through an expatriate's informed lens of being immersed in the local culture over an extended period. The discourse highlights the significance of international connections while asserting Southeast Asian relevance and context as the discipline of art therapy matures in this region.
\end{abstract}

Keywords: art therapy, postgraduate training, Singapore, ANZACATA, East/West, culture

\section{Introduction: Reflections, Setting the Stage}

As a relatively nascent profession overall, art therapy has been gaining much ground in seeking new territory globally with practice and training evolving to address the specific cultures, traditions, and mental health within those areas (Kelly, Levey, \& Lay, 2017; Lay, 2016; Reader, 2018). Over the past several years, art therapy throughout Asia has been introduced, established, and developed. Oftentimes, there are visiting arts therapy practitioners, academics, and researchers who lead time-limited workshops and trainings, and then there are others living in-country who are navigating sometimes difficult terrain to fully anchor the discipline. Some countries in Asia, Singapore for example, have also established postgraduate training programs that have been central in proactively training qualified resident art therapists who are fully equipped to practice in ways that are culturally relevant and meaningful within Asian contexts. 
As with many professional disciplines in the West that are regulated through awarded credentials for qualified candidates, it becomes necessary and imperative for the discipline of art therapies in the East, to be legitimate, of high caliber, and to be guided by best practices, standards, and ethics, especially if credentials are to be granted and maintained. This remains the same for postgraduate training programs and for continuing professional development activities. Professional governing bodies, including membership organizations, are designed and structured to rigorously address these important constructs. Not all countries have such organizations with regulatory or credentialing authority and practitioners may need to look outside of their resident country; at present, this is the case for Singapore (although highlighted here, this will be further addressed in the next section, Postgraduate Training, the Profession, and International Connections).

For those of us in Singapore and in Southeast Asia, the closest such organization is the Australian, New Zealand and Asian Creative Arts Therapies Association (ANZACATA). This organization is uniquely positioned, geographically and philosophically, in terms of art therapy practice, training, and the ongoing development of this discipline in the Asia Pacific region (Kelly et al., 2017). Acknowledgement of, respective for, and an embracing of culture, cultural traditions, and practices that are culturally relevant are the fundamental core of this art therapy membership organization.

A critical and multipronged relationship has been established among ANZACATA, Singapore, and the MA Art Therapy training program at LASALLE College of the Arts, Singapore (Kelly et al., 2017; Lay, 2016). ANZACATA provides guidelines and standards for best practices, ethics, and training, and they also grant the professional credential for those practicing in Singapore (Lay, 2016). Being aligned to this organization has enhanced the integrity, accountability, and reception of the training by our international peers and has allowed us to assert our identity, presence, and practice locally and in the region; in fact, this seems to have set the standard and/or raised the bar in Southeast Asia. This alignment has been mutually beneficial as ANZACATA has broadened its international profile, membership has increased, and there has been effective collaboration, exchange, and dialogue among and between cross-national members.

The aim of this study was to provide a reflective account of my perspective on the unique East/West nature and role of ANZACATA and on art therapy in Singapore through my role as program leader of the first and only postgraduate psychodynamic art psychotherapy training in Southeast Asia. This perspective is further informed through substantial experience as a credentialed art therapist bridging Eastern and Western countries, cultures, clinical practices, and professional art(s) therapy organizations. This article was written and articulated through an expatriate's informed lens of being immersed in this local culture over an extended period. The discourse highlights the significance of international connections while asserting Southeast Asian relevance and context as the discipline of art therapy matures.

Reflecting upon the invitation to write a perspective on the development of art therapy in Southeast Asia, with consideration to the significance of East/West influences, 
relations, and training, I first turned to my own art practice to contemplate this on a deeper and visual level. Since landing in Southeast Asia, my own art practice has been transformed in both content and medium, transitioning from provocative conceptual assemblages with found objects to a more spontaneous and on-the-spot deliberate snapshot of the moment through photography. The photograph, Self-Portrait in Singapore 2019 (Figure 1), was taken shortly after a brief online video discussion with global leaders in arts and expressive art therapies with sophisticated insight and understanding of creative arts education and therapy in the complex contexts of East/ West traditions. I was intrigued by this invitation and felt compelled to carefully navigate a narrative that others might find just as interesting and wondered if there would be a sense of universality to it or would it remain location-specific.

This photograph, my first purposeful attempt at exploring these topics and experiences over the last eight years in a more formalized format, grounded and centered my process, my thoughts, and my reflections. Through my own physical holding of the golden gilded disc, a mirror of sorts in the image, I was deliberately confronted with my reflection, with some features in focus while others in distortion. I was struck by the interrelationships between the constructs of the artwork components, such as light and dark, perspective and focus, foreground and background, and how these contributed to the comprehensive whole, whether apparent or not, and in metaphoric ways were linked to the myriad of possible associations linked to the composition of this article.

Although only myself appeared in the image, I do imagine others there in dialogue with me, challenging my perceptions and understanding of East/West, of trying to make sense of cultural implications, mine and of those I meet in this part of the world, and of my oftentimes steep learning curve in terms of shifting presence in oscillating states of individualistic and then collectivist communities. I notice that this is even more pronounced when I try to explain to people what it is that I do in Asia to those back in the West, and when I try to explain to those in the East what I used to do when I lived in the West and how I am involved in developing the discipline of art therapy in their region and so forth. The explanations are similar yet different and are dependent upon where I am, physically and sometimes mentally, at that moment.

Translocating among three countries has afforded me opportunities to truly appreciate the complexities of culture, tradition, identity, boundaries, and community within professional contexts. Although a privilege, navigating and negotiating these complexities have been difficult at times, even overwhelming at others; however, the rich and insightful learning that these inherently present(ed) have been well received and incorporated into my perspectives on the need for connection, conversation, and collaboration especially within the territory of an ever-evolving discipline such as art therapy. In addition to a transcontinental shift from Napa, California, to Singapore in 2011, my career took on a significant transition from being a clinical practitioner within forensic mental health with certain requisite skill sets to being an academic in higher education, wherein I quickly assumed the leadership of a postgraduate art therapy program (LASALLE, 2017; Lay, 2016). The next section delves deeper with the topics and my perspective of the unique nature and role of ANZACATA. 

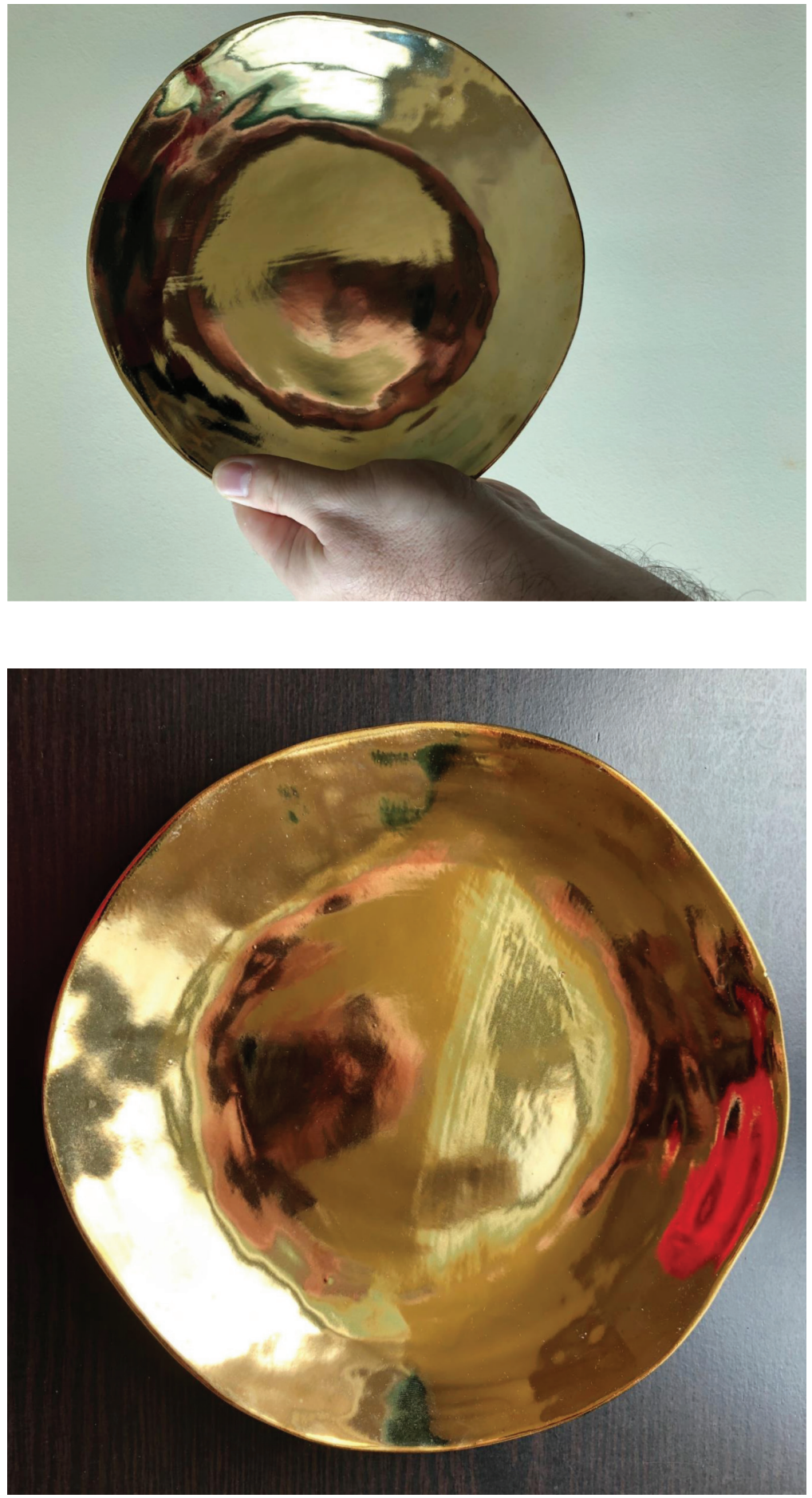

FIGURE 1 | R. Lay, Self-Portrait in Singapore 2019, 2019, digital photograph (cropped) 


\section{Postgraduate Training, the Profession, and International Connections}

In the island city-state of Singapore, it is acknowledged that there are several art therapy pioneers, Singaporean and expatriates, who have introduced this discipline several years prior to a postgraduate training being established at LASALLE College of the Arts and that sustaining relationships with these pioneers have been critical to the ongoing development and recognition of this discipline at various levels throughout the nation (Lay, 2016).

The training program at LASALLE was written in 2005, with the inaugural cohort commencing in 2006. The program was developed from the training standards of the major international art(s) therapy professional organizations from the United Kingdom, the United States, Australia, and New Zealand and was further informed by the Quality Assurance Agency for Higher Education in the United Kingdom. Although much of the theory, literature, and research that is utilized is underpinned from the West, there has been a concerted effort to integrate into the pedagogy and curriculum cultural relevance, philosophy, and emerging research that are meaningful to and within Asian contexts (Kelly et al., 2017; LASALLE, 2017; Lay, 2016; Reader, 2018). Understandably, cultural relevance is rather complex and at times difficult to clearly articulate; however, practices and concepts of mindfulness, filial piety, face, and even traditional materials in this region such as ink, paper, bamboo, and rice powders to name just a few, have been embraced within the discipline. Volumes can be written on cultural relevance especially in art therapies, however, in this present article, a fuller discussion is beyond the current scope.

From 2007 to 2018, we have graduated 147 art therapists, and we are set to graduate another 14 in August 2019. The student profile is typically comprised of Asian students, with approximately half being Singaporean and the other half coming from around the region and abroad. Some students are expatriates who are already living in Singapore; however, they are classified as international. Yearly, through clinical placements and community arts projects, students provide approximately 12,000+ hours of art therapy services (Lay, 2016). LASALLE, therefore, not only plays a major role in developing the discipline of art therapy in this region, but they also prepare qualified art therapists who, during their rigorous training, make a significant contribution and impact on the overall local mental health and well-being of a diverse population. Indeed, this involves a tremendous amount of work and responsibility.

Year on year, I have observed that potential students from around the globe are looking to our program and I believe that part of the reason stems from our deliberate relationships with international connections, including the invitation of distinguished and world renowned art therapy practitioners, educators, and researchers to Singapore through our annual Artist-in-Residence series, and through our intentional global outreach in terms of asserting our presence and participation at high-profile conferences, collaboration with prestigious industry partners, and through our community arts projects that purposefully instigates dialogue in creative ways on topics that are typically taboo and/or off-limits in Asia. Students report that they selected our training given our strong emphasis on culture, cultural contexts, our collaboration and community arts 
projects with a range of industry partners locally and abroad, our academic standing and integrity as an approved postgraduate art therapy training program by ANZACATA, and for our overall global outlook (LASALLE, 2017; Lay, 2016).

Given my nationality, my employment history, and my resident status, I maintain Board Certification and Registration with the American-based Art Therapy Credentials Board (ATCB). Upon arrival in Singapore and given my new role as program leader, I purposefully applied for and was successfully granted registration with ANZACATA. This has proven to be crucial in my understanding and direct involvement with building, developing, and promoting a sustainable training program and mental health modality in Southeast Asia.

These credentials, including those granted by ANZACATA, have been essential in positioning credence and integrity to my reception, to my role, to my active engagement, and to my leadership in Asia (Reader, 2018). In fact, all teaching staff are qualified art therapists and all are credentialed with ANZACATA; again, this asserts our level of professionalism and models to our students, alumni, and the mental health community that we are bound by ethics, best practices, and standards. It is from this authority that we also appreciate, acknowledge, and advocate for international connections while also asserting Asian relevance and context in postgraduate training, in the creation of art therapy positions, in evolving best practices and ethical guidelines that are proactively aligned to local laws and ways of working and, of course, in art therapy practice in Asia.

As the discipline matures, it has been important to strategically mentor and enhance competencies, confidence, and currency of practice to international standards with the aim to assert, showcase, and highlight the significant work that is being conducted in this part of the world in Asian contexts (Reader, 2018). Doing so has increasingly allowed local perspectives to be identified and acknowledged, which, in turn, have further informed the local postgraduate art therapy program in its attempt to more accurately provide training that is culturally informed, meaningful, and relevant in Asia.

Admittedly, it has been just as strategic and perhaps necessary to be linked to a professional art(s) therapy organization to ensure that the training is recognized as being on par with similar training programs from around the world and that there is a credible credentialing governing body that can cater to the various professional needs, including standards and guidelines, ethics, and continuing professional development, of the growing number of qualified art therapists practicing in Singapore and the region (Reader, 2018). Geographically, it was only logical that Singapore develop sustaining links to ANZACATA, the nearest such organization.

ANZACATA is a multicountry and multitiered membership organization which has played a pivotal role in the development and the promotion of the arts therapies in the Asia-Pacific region (Kelly et al., 2017). They have created documents for standards, ethics, best practices, and training; they review and grant professional credentials to qualified arts therapists; and they provide opportunities for ongoing professional development through international conferences and symposia that rotate among countries; in 2014, LASALLE hosted a 2-day symposium in Singapore (ANZACATA, 2018; LASALLE, 2017). 
As part of their mandate, they maintain a comprehensive website with resources for their members and for the public, and they publish a yearly journal. This organization recognizes and celebrates difference and inclusion and have promoted the development of regional groups acknowledging the need for arts therapists to build professional communities to further develop opportunities for professional development, community, and a forum to discuss their region-specific needs, which are then brought back to the larger organization through regional group reports, newsletters, board meetings, and through their annual general meeting.

As students began to complete their training at LASALLE, it became necessary for them to become credentialed and members of a professional body. As such, links to the Australian and New Zealand Arts Therapy Association (ANZATA) were made, with ANZATA reviewing the program and granting approval status in 2009. This was a significant milestone, as it not only acknowledged the level of training by an international arts therapy professional organization, but it also allowed our graduates to apply for ANZATA's credential AThR (Registered Art Therapist), meaning that they can work as a registered art therapist in Singapore, Australia, and New Zealand (LASALLE, 2017). Alumni of our program have migrated in these three countries, and elsewhere, and have been able to transfer their training and credentials with them, and some have also qualified for additional credentials within those countries.

Through my varied relationships and interactions with the leadership and members of ANZACATA, under a range of auspices that include credentialed professional, educator of an approved postgraduate training program, committee member, and blindpeer reviewer of their international journal to name a few, I have come to understand that ANZACATA has a long-standing and inherent respect for, sensitivity to, and synergy with peoples of all nations especially those within Asia Pacific. The leadership has been approachable, inclusive, and willing to share resources, insights, and their wisdom of working within and among different cultures, countries, and distinctive regions. In fact, they welcome and support a wide spectrum of practitioners from various countries as evidenced by their recent name change from ANZATA to ANZACATA in July 2018; this had been a part of the organization's discussions for several years (Kelly et al., 2017).

For postgraduate students, the connection with ANZACATA has proven invaluable for several reasons, including direct networking with other students training in Australia and New Zealand. Students in their final year receive complimentary trainee memberships, and they also have access to arts therapy resources, practitioners, academics, and researchers through the ANZACATA website. In 2014, our training program collaborated with ANZACATA to co-organize an international arts therapy research and professional practice conference and, as stated earlier, this was hosted at LASALLE College of the Arts in Singapore (Lay, 2016).

This conference was strategically designed to showcase the emerging practice and research from Singapore and the region, with our local and international colleagues, through a structured and organized framework. It aimed to enhance local practitioner confidence, allow local talent to be showcased, and purposefully encourage the significant clinical material, both research and practice, to be shared with others. Oftentimes, there 
has been a seeming over-reliance or even preoccupation with expertise from the West. However, this conference showcased the significant work introduced and developed locally and within the region, emphasizing Asian content and contexts. This co-organized conference was successful for many reasons, and it also evidenced a highly sophisticated East/West collaboration that was mutually beneficial.

Increasingly, practitioners from Singapore and Southeast Asia are making a strong presence at ANZACATA's international events, and this has been well received. For several years, there was a member from Singapore serving as the Singapore representative on ANZACATA's board. At least five of the six Singapore representatives that have served on this board were from Singapore. Their presence has been quite important and well received by their counterparts in Australia and New Zealand, given their local experience, knowledge, networks, and understanding of the local and regional mental health landscapes and contexts wherein they train and practice, as well as the professional needs of the membership in Singapore and the region. In tandem, the Singapore representatives have also learned a great deal in terms of how an international professional arts therapy membership organization functions, is governed, and is structured. This in turn is shared with colleagues back in Singapore, wherein further discussion is stimulated and ideas on how best to enhance, advocate for, and develop the profession of art therapy in Singapore is instigated.

Although ANZACATA is a longer-established and recognized organization, and although they are the only art therapy organization to officially grant a professional credential to art therapists in Singapore and the region, as well as review and, if all training requirements and standards are successfully evidenced, grant approval status to postgraduate art therapy training in this region, there is still a critical need to have an in-country professional art therapy organization. Several of our teaching staff are members of the Art Therapists' Association Singapore (ATAS), and our students are encouraged to become members of both organizations, given that they most likely will reside and practice in this region.

ATAS was formally established in 2008 to address the needs of the art therapy community, with a majority of the founding members being graduates of the MA Art Therapy program at LASALLE (ATAS, 2018; Kelly et al., 2017). This membership organization has asserted their own presence within the mental health landscape locally, they developed their own set of localized ethics and guiding principles, and they continue to develop and gain traction in regard to promoting the discipline and practice locally. Situated within this context, ATAS is one of four key collaborative driving forces of the profession in Singapore. The others being LASALLE College of the Arts, ANZACATA, and The Red Pencil Humanitarian Mission; all regularly collaborate with each encouraging active student involvement. As LASALLE is centrally located, several meetings, collaborative projects, and professional development activities take place there.

The Red Pencil Humanitarian Mission was founded by one of the first graduates of LASALLE's MA Art Therapy program, and it aims to provide a variety of art therapy services in Singapore, the region, and around the globe. These services provide a range of opportunities to credentialed arts therapists and to the postgraduate students at 
LASALLE as well as to qualified international art therapists. LASALLE College of the Arts is the Educational Partner with The Red Pencil Humanitarian Mission and we fully acknowledge how important this relationship is for the discipline, for qualified arts therapists, and for the students (LASALLE, 2017; Lay, 2016).

The rapid and successful expansion of this foundation is a wonderful example of how Singapore is increasingly becoming recognized as having specialized expertise and how this is being shared regionally and internationally. This further echoes the statement of Kelly et al. (2017) that, "Arts therapists in Australia, New Zealand and Singapore are now looking less to Europe and the United States and more increasingly towards our own geographical and cultural region of Asia Pacific" (p. 22), and it also demonstrates how local talent is being nurtured, enhanced, and asserted.

In Singapore, aligning with a professional arts therapy organization such as ANZACATA has been advantageous for several reasons as outlined throughout this section. From art therapy's humble introduction and beginnings to its current positioning as a global and culturally informed, relevant, and meaningful application to practice in Asia, Singapore continues to embrace international connections while at the same time asserting itself as an ambassador for the discipline that champions both East and West.

\section{A Solid Foundation: Final Thoughts}

A sustaining relationship with the ANZACATA, given their unique East/West nature and role, has been critical in allowing art therapy practice and postgraduate training in Southeast Asia to assert itself nationally and internationally. In a contemporary approach to postgraduate art therapy training in Singapore, and perhaps Asia for that matter, wherein globalization is at the forefront of major discourse, it is impossible and impractical to fully tease out the West from the training and/or from the influence on the development of the arts therapies in this part of the world. What is essential, however, is that the discipline of arts therapies continues to develop in Asia in ways wherein Asian theory, literature, and research take precedence and center stage given the unique, rich, and complex cultures, customs, and traditions found here.

Revisiting the photograph, Self-Portrait in Singapore 2019 (Figure 1), I do acknowledge my reflection and admit that not all others may see what I see from this perspective. Images, just like perspectives and the topics of this article, are multilayered, complex, and influenced by one's own culture, background, and experience.

I do believe that a blend of East/West is important and relevant; that each has much to offer to the global art therapy community; that we will continue to progress the arts therapies in ways that are profound, meaningful, and relevant in cultural contexts; and I envision that the discourse will continue to challenge, to stimulate, and to be provocative. International connections with ANZACATA and with others will remain significant with perhaps even more reciprocity, purpose, and understanding with and among practitioners, academics, artists, researchers, students, stakeholders, and a full range of communities and participants. 


\section{About the Author}

Ronald P.M.H. Lay, EdD (candidate), MA, AThR, ATR-BC, program leader, MA Art Therapy, School of Creative Industries, Faculty of Fine Arts, Media \& Creative Industries, LASALLE College of the Arts, Singapore. Ronald.lay@lasalle.edu.sg

\section{Conflicts of Interest}

The author declares no conflict of interest.

\section{References}

Art Therapists' Association of Singapore (ATAS). (2018). Code of ethics and principles of professional practice. Retrieved from http://www.atas.org.sg/uploads/9/8/4/1/98411684/atas-code-of-ethics-andprinciples-of-professional-practice.pdf

Australian, New Zealand and Asian Creative Arts Therapy Association (ANZACATA). (2018). Standards of professional practice and code of ethics. Retrieved from https://www.anzacata.org/resources/ Files/3_ABOUT/ANZACATA_CodeofEthics.pdf

Kelly, J., Levey, A., \& Lay, R. (2017). Forwarding arts therapy in South East Asia. Creative Arts in Education and Therapy: Eastern \& Western Perspectives, 3(1), 14-25.

LASALLE College of the Arts. (2017). Postgraduate masters in art therapy prospectus. Singapore: LASALLE College of the Arts.

Lay, R. (2016). Introduction to art therapy in Singapore. Keynote paper presented at the Taiwan, Hong Kong and Singapore Creative Arts Therapy Exchange: Symposium and Workshops Towards Health on Body, Mind and Spirit Symposium, Hong Kong.

Reader, A.E. (2018). Global art therapy. In R. Carolan \& A. Backos (Eds.), Emerging perspectives in art therapy: Trends, movements, and developments (pp. 134-154). New York, NY: Taylor \& Francis. 